\title{
Antibody-Free Rapid Detection of SARS-CoV-2 Proteins Using Corona Phase Molecular Recognition to Accelerate Development Time
}

\author{
Soo-Yeon Cho, Xiaojia Jin, Xun Gong, Sungyun Yang, Jianqiao Cui, and Michael S. Strano*
}

Cite This: Anal. Chem. 2021, 93, 14685-14693

Read Online

ABSTRACT: To develop better analytical approaches for future global pandemics, it is widely recognized that sensing materials are necessary that enable molecular recognition and sensor assay development on a much faster scale than currently possible. Previously developed severe acute respiratory syndrome coronavirus 2 (SARS-CoV-2) point-of-care devices are based on the specific molecular recognition using subunit protein antibodies and protein receptors that selectively capture the viral proteins. However, these necessarily involve complex and lengthy development and processing times and are notoriously prone to a loss of biological activity upon sensor immobilization and device interfacing,
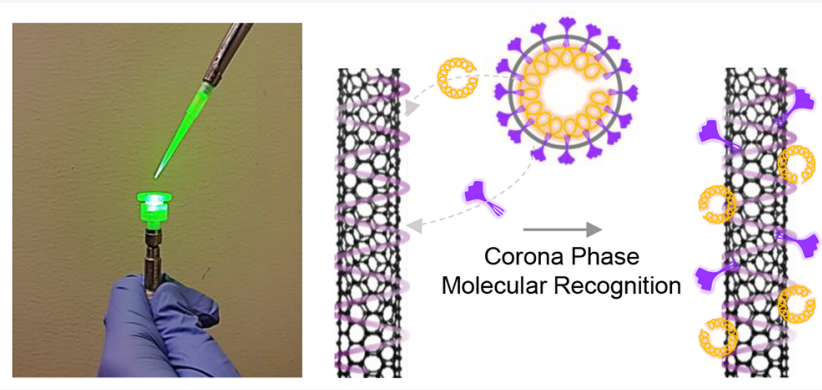
potentially limiting their use in applications at scale. Here, we report a synthetic strategy for nanoparticle corona interfaces that enables the molecular recognition of SARS-CoV-2 proteins without any antibody and receptor design. Our nanosensor constructs consist of poly(ethylene glycol) (PEG) - phospholipid heteropolymers adsorbed onto near-infrared (nIR) fluorescent single-walled carbon nanotubes (SWCNTs) that recognize the nucleocapsid (N) and spike (S) protein of SARS-CoV-2 using unique threedimensional (3D) nanosensor interfaces. This results in rapid and label-free nIR fluorescence detection. This antibody-free nanosensor shows up to $50 \%$ sensor responses within $5 \mathrm{~min}$ of viral protein injections with limit of detection (LOD) values of $48 \mathrm{fM}$ and $350 \mathrm{pM}$ for $\mathrm{N}$ and $\mathrm{S}$ proteins, respectively. Finally, we demonstrate instrumentation based on a fiber-optic platform that interfaces the advantages of antibody-free molecular recognition and biofluid compatibility in human saliva conditions.

\begin{abstract}
A rapid and accurate detection of severe acute respiratory - 1 syndrome coronavirus 2 (SARS-CoV-2) infection is critical for reducing the morbidity of Coronavirus Disease 2019 (COVID-19). ${ }^{\text {. }}$ The current methodology in assessing the present infection of SARS-CoV-2 relies on two analytics: (i) nucleic acid-based tests (NATs), which detect the genetic material (RNA) from SARS-CoV-2 and (ii) serological tests, which detect the presence of antibodies (IgG and IgM) against SARS-CoV-2. ${ }^{2}$ NAT primarily uses reverse-transcription polymerase chain reaction (RT-PCR) to amplify and detect the SARS-CoV-2 RNA in the patient. Since RT-PCR demonstrates superior sensitivity for viral RNA detection with a limit of detection (LOD) of a few viral RNA copies, the NAT is the preferred testing method to diagnose SARS-CoV-2 positive cases to date. ${ }^{3}$ However, this method is composed of highly complex processes, which require specialized equipment, trained personnel, and long turnaround time, limiting the high-throughput diagnosis of large populations and wide testing accessibility in rural regions. ${ }^{4-6}$ Serological test, in general, is based on lateral flow immunoassay (LFA) platform, which is relatively easy, inexpensive, having a short turnaround time, and amenable to point-of-care diagnostic methodologies. ${ }^{7}$ However, the sensitivity of the antigen test is
\end{abstract}

generally not high enough to accurately screen the positive cases and provide past viral infections data. Thus, it is hard to identify the currently active cases. ${ }^{7-9}$ Therefore, there has been a strong drive to find a next-generation viral testing technology for faster and simpler diagnostics of large populations, which can directly detect viral antigens in clinical samples without complicated sample preparation steps. In addition, even though NAT and LFA-based diagnostics have a lot of advantages, we could not have a wide deployment of these test kits until few months of the early phase of the pandemic due to complicated development processes, including sensor design, validation and implementation, and shortages of laboratory item. ${ }^{10,11}$ Thus, an accelerated point-of-care sensor development process should be developed for future viral targets.

Received: July 8, 2021

Accepted: September 22, 2021

Published: October 26, 2021 
a

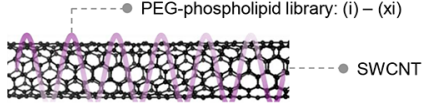

(iii) 18:0 PEG2000 PE

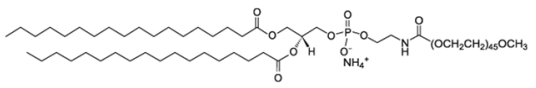

(vi) 14:0 PEG2000 PE

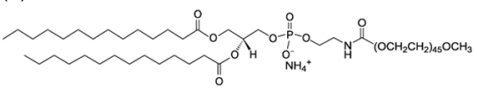

(ix) DSPE-PEG5000 Amine

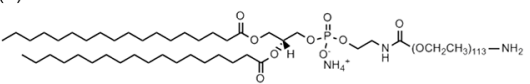

b

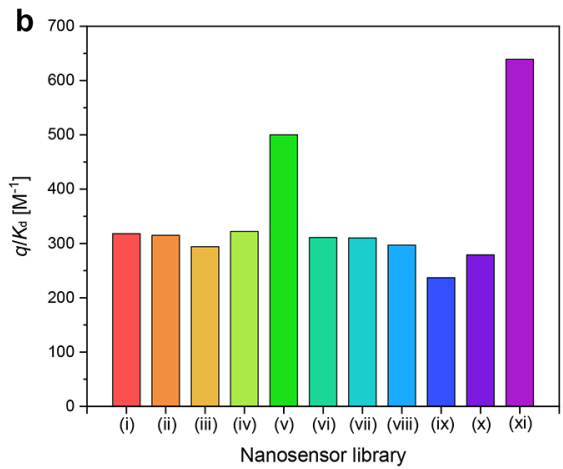

(i) 14:0 PEG5000 PE

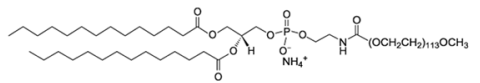

(iv) 18:0 PEG5000 PE

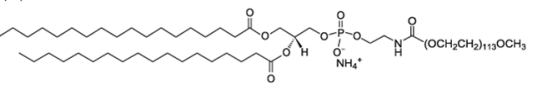

(vii) 16:0 PEG5000 PE

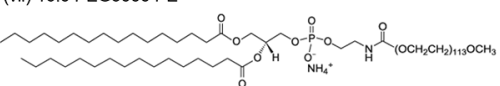

(x) DSPE-PEG2000 Carboxylic Acid

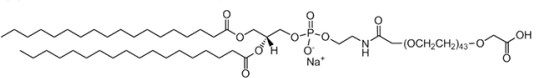

(ii) 18:0 PEG1000 PE

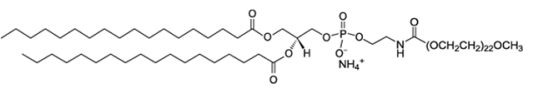

(v) 16:0 PEG2000 PE

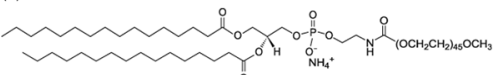

(viii) 14:0 PEG1000 PE

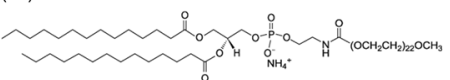

(xi) 16:0 PEG1000 PE

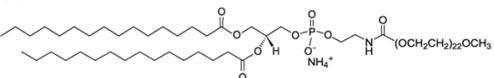

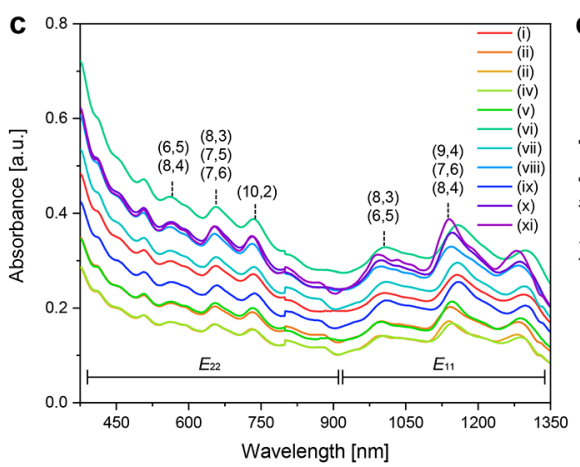

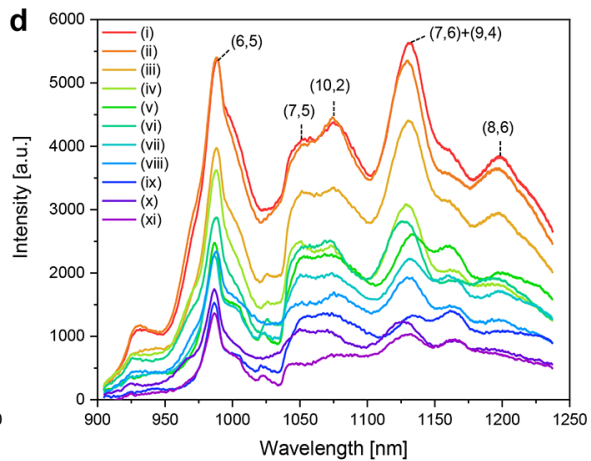

Figure 1. SARS-CoV-2 protein nanosensor library. (a) PEG-phospholipid library for CoPhMoRe-based SWCNT nanosensors. (b) Accessible surface area of the PEG-phospholipid wrapped SWCNTs, where $q$ is the vacant binding site on SWCNTs, and $K_{d}$ is the dissociation constant of probe binding to SWCNTs. Assuming an equivalent probe binding strength $K_{\mathrm{d}}$, a higher $q / K_{\mathrm{d}}$ value represents more accessible surface area and less corona phase coverage. (c) UV-vis-nIR absorption spectrum of PEG-phospholipid/SWCNT nanosensor library with distinct $E_{11}$ and $E_{22}$ transitions. (d) nIR fluorescence spectrum of PEG-phospholipid/SWCNT nanosensor library under $785 \mathrm{~nm}$ excitation.

Several potentially useful new analytics for rapid and sensitive SARS-CoV-2 detection have emerged for the diagnosis of COVID-19 against RT-PCR and serological tests, including field-effect transistor (FET) sensing devices $^{12-14}$ electrochemical cell devices, ${ }^{15-17}$ plasmonic resonance platform, ${ }^{18-20}$ optical nanosensors, ${ }^{21-23}$ and chemiresistors. ${ }^{24}$ These analytic tools showed sensitive and rapid detection performances based on simple sensor signal readout without complex sample processing and specialized equipment. However, all of these methods are based on specific and complex surface chemistry design of substrate and transducers using subunit protein antibody and protein receptors such as DNA/RNA aptamers and angiotensin-converting enzyme 2 (ACE2) to selectively capture the SARS-CoV-2 viral proteins. $^{25-27}$ These antibody or protein receptor functionalizations are expensive, fragile, prone to loss of biological activity with external treatment such as immobilization and device interfacing, and exhibit significant batch-dependent variations. ${ }^{28,29}$ In addition, they involve multiple processing steps of fabrications, including incubation, protein synthesis, and washing steps that require a significant amount of time to perform, limiting their use in widespread applications. ${ }^{30}$

Herein, we address this challenge using corona phase molecular recognition (CoPhMoRe) that enables the molecular recognition of SARS-CoV-2 viral proteins without the need for antibody or enzymatic receptor incorporation. Our recognition motif consists of specifically selected poly(ethylene glycol) (PEG) - phospholipid heteropolymers adsorbed onto and structured by an underlying single-walled carbon nanotube
(SWCNT), whereby a unique three-dimensional (3D) nanoparticle interface recognized nucleocapsid $(\mathrm{N})$ and spike $(\mathrm{S})$ protein of SARS-CoV-2 virus, resulting in rapid and label-free modulation of SWCNT near-infrared (nIR) fluorescence. The presence of the $\mathrm{N}$ and $\mathrm{S}$ proteins of SARS-CoV-2 elicits robust and rapid nanosensor fluorescence changes up to 50 and $40 \%$ within $5 \mathrm{~min}$ of analyte injections, and LOD vaues were measured to be $48 \mathrm{fM}$ and $350 \mathrm{pM}$, respectively. We also characterize the nanosensor stability in $100 \%$ human saliva condition and demonstrate that the $\mathrm{N}$ protein sensing ability is completely preserved. Finally, an on-site diagnosis system is demonstrated with a fiber-optic (optode) benchtop platform that interfaces the advantages of antibody-free molecular recognition virus sensors on a $3 \mathrm{D}$ sensing tip.

\section{RESULTS AND DISCUSSION}

SWCNTs synthesized by the high-pressure carbon monoxide (HiPCO) process were suspended with a specifically designed library of 11 PEG-phospholipid polymers capable of forming corona phases at the SWCNT surface (Figure 1a). PEGphospholipid polymers are chosen for corona formation since previous studies have shown that PEG-phospholipid-wrapped SWCNTs were capable of detecting proteins in complex biofluid conditions. ${ }^{31}$ In addition, the chain length of PEG can be easily tuned to form a wide range of the binding pocket, and they are commercially available; thus, the preparation of polymer library is not time consuming. The accessible surface area of the PEG-phospholipid-wrapped SWCNT was measured by titration using a quenchable fluorescent riboflavin 

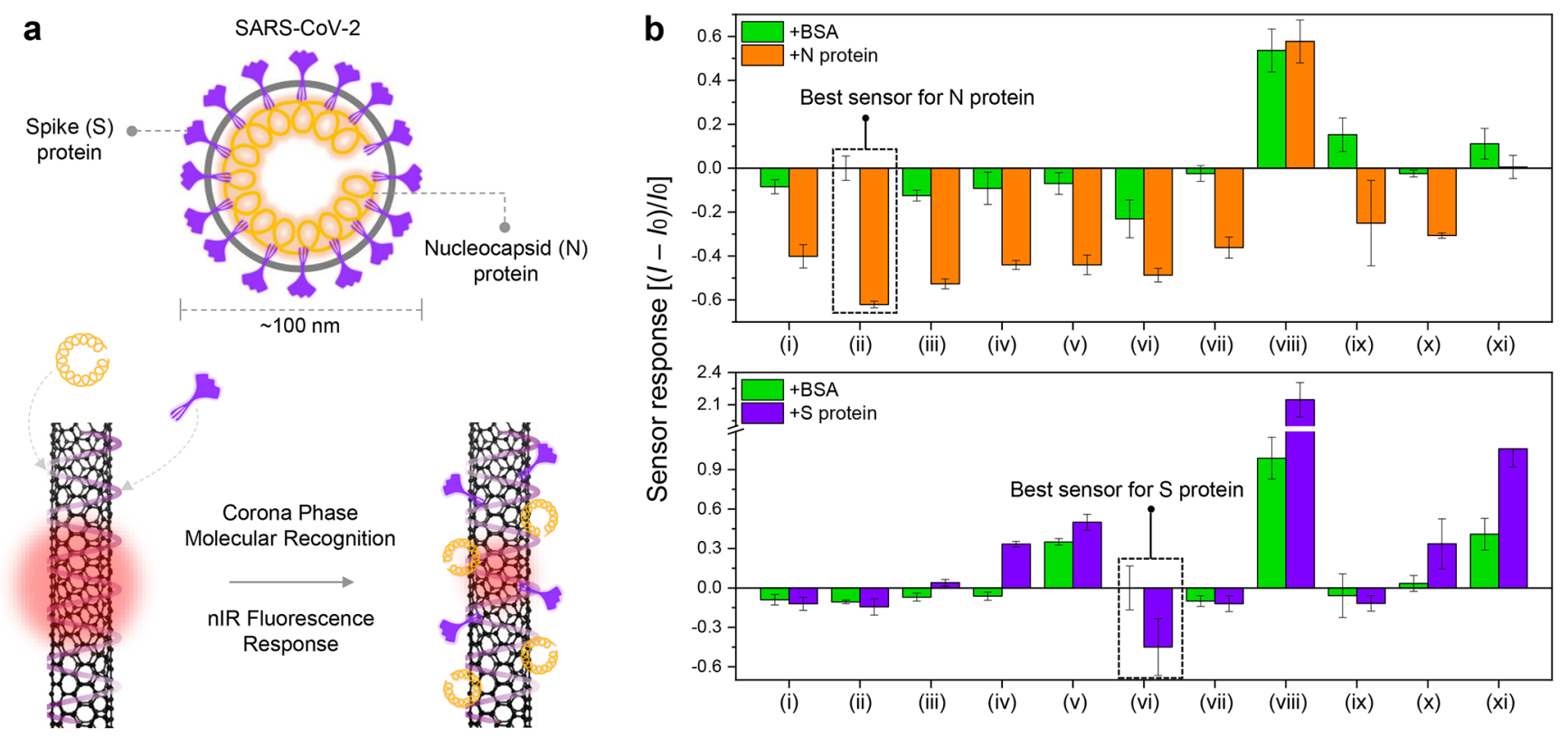

Figure 2. SARS-CoV-2 protein nanosensor characterizations. (a) Schematic of CoPhMoRe mechanism of PEG-phospholipid/SWCNT nanosensors on $\mathrm{N}$ and $\mathrm{S}$ viral proteins. (b) Screening results of the integrated normalized response of nanosensors library on $\mathrm{N}$ protein (top) and $\mathrm{S}$ protein (bottom). Dashed lines indicate the best nanosensor for each protein. The SWCNT and protein concentration (N protein, $\mathrm{S}$ protein, BSA) were $0.5 \mathrm{mg} / \mathrm{L}$ and $10 \mu \mathrm{g} / \mathrm{mL}$, respectively. $\mathrm{N}$ protein buffer: $15 \mathrm{mM} \mathrm{Na}_{2} \mathrm{HPO}_{4}, 5 \mathrm{mM} \mathrm{NaH}_{2} \mathrm{PO}_{4}, 0.25 \mathrm{M} \mathrm{NaCl}$, and pH 7.5, $\mathrm{S}$ protein buffer: 2 $\mathrm{mM}$ Tris, $200 \mathrm{mM} \mathrm{NaCl}$, and $\mathrm{pH}$ 8.0. Data are mean (bar) $\pm \sigma$ (error bar), with $n=3$ replicates.

probe, following a recently developed molecular probe adsorption (MPA) technique (detailed procedure in Supporting Information Note 1). ${ }^{32}$ The results show that DSPEPEG5000 Amine formed the largest surface covering corona on SWCNT, and 16:0 PEG1000 PE formed the smallest surface coverage corona (Figure $1 \mathrm{~b}$ ). The resulting colloidal solutions of nanosensors are characterized by ultravioletvisible-nIR (UV-vis-nIR) absorption spectroscopy. Figure 1c shows the UV-vis-nIR absorption spectrum for the PEGphospholipid corona phase, where the distinct and sharp peaks of $E_{11}$ and $E_{22}$ transitions indicate the successful isolation and suspension of individual SWCNT. nIR fluorescent emission spectra (Figure 1d) under $785 \mathrm{~nm}$ laser excitation demonstrate that nanosensors are mainly composed of $(6,5),(7,6)$, and $(9$, 4) nanotube chirality.

The nIR fluorescence response of PEG-phospholipid/ SWCNT nanosensors was measured during SARS-CoV-2 N and $S$ protein addition, schematically represented in Figure $2 \mathrm{a}$. The $\mathrm{N}$ and $\mathrm{S}$ proteins can be recognized by specific $3 \mathrm{D}$ corona phase configurations of the PEG-phospholipid polymers imposed by the nanoparticle interfaces enabling rapid modulation of underlying nIR fluorescence intensity of the nanotube. ${ }^{31,33}$ In this way, the corona phase (PEGphospholipid) acts as the receptor coupled directly to the fluorescent nanotube, which acts as the nonselective transducer. Note that specific recognition between the PEG and phospholipid independently of the nanotube surface is not expected. The combined polymer/nanotube construct is labeled CoPhMoRe. The unit compositions of the polymers were varied to produce structurally diverse corona phases to sample a range of free volumes and chemical interactions with the analyte, influencing the dynamic binding/unbinding of viral proteins. ${ }^{34}$ In total, we explored 44 unique corona phases in this work based on 11 PEG-phospholipid polymer backbones. The responses of the resulting fluorescent emission of this library were recorded following a $1 \mathrm{~h}$ incubation with each viral protein target at $10 \mu \mathrm{g} / \mathrm{mL}$ in distinct buffer conditions. An identical concentration of strongly adsorbing bovine serum albumin (BSA) was used as an interferent to address both issues of nonspecific binding and the stability of the sensor. The resulting bar graph chart of molecular binding shows distinct fluorescence responses $\left(\left(I-I_{0}\right) / I_{0}\right)$ with varying polymer compositions (Figure $2 \mathrm{~b}$ ). Here, $I_{0}$ and $I$ represent the integrated $\mathrm{nIR}$ intensity of nanosensors at $t=0$ and after viral proteins injection, respectively. Each nanosensor shows a unique turn-on or turn-off response to $\mathrm{N}$ proteins, $\mathrm{S}$ proteins, and BSA, with response intensity changes from -70 to $212 \%$. Most of the sensors demonstrate quenching or turnoff responses to $\mathrm{N}$ protein and intensity gains or turn-on responses to $S$ protein. The 18:0 PEG1000 PE/SWCNT (henceforth labeled nanosensor ii) and 14:0 PEG2000 PE/ SWCNT (nanosensor vi) show the most obvious and clearly distinguishable responses to $\mathrm{N}$ protein and $\mathrm{S}$ proteins, respectively, with strong 50 to $70 \%$ decreases in fluorescence intensity. Importantly, BSA appears to induce almost no response for these corona phase complexes. Thus, for the purposes of this work, nanosensor ii and nanosensor vi can be considered specific sensors for $\mathrm{N}$ protein and $\mathrm{S}$ proteins, respectively. Fluorescent emission spectra demonstrate that nanosensor ii and nanosensor vi show significant nIR intensity decreases only to their specific protein targets (Figure S2a). Time-series emission spectra show that intensities of both nanosensors do not change after $60 \mathrm{~min}$ of buffer incubation; however, they drastically change within $5 \mathrm{~min}$ of the addition of viral proteins (Figure S2b). More specifically, the normalized change in the fluorescence of the $1125 \mathrm{~nm}$ emission peak corresponding to $(7,6)$ chirality SWCNT instantaneously decreased by 57 and $45 \%$ within 5 min (Figure S3) for nanosensor ii and nanosensor vi, respectively. The fluorescent response of nanosensor ii to $\mathrm{N}$ protein was 

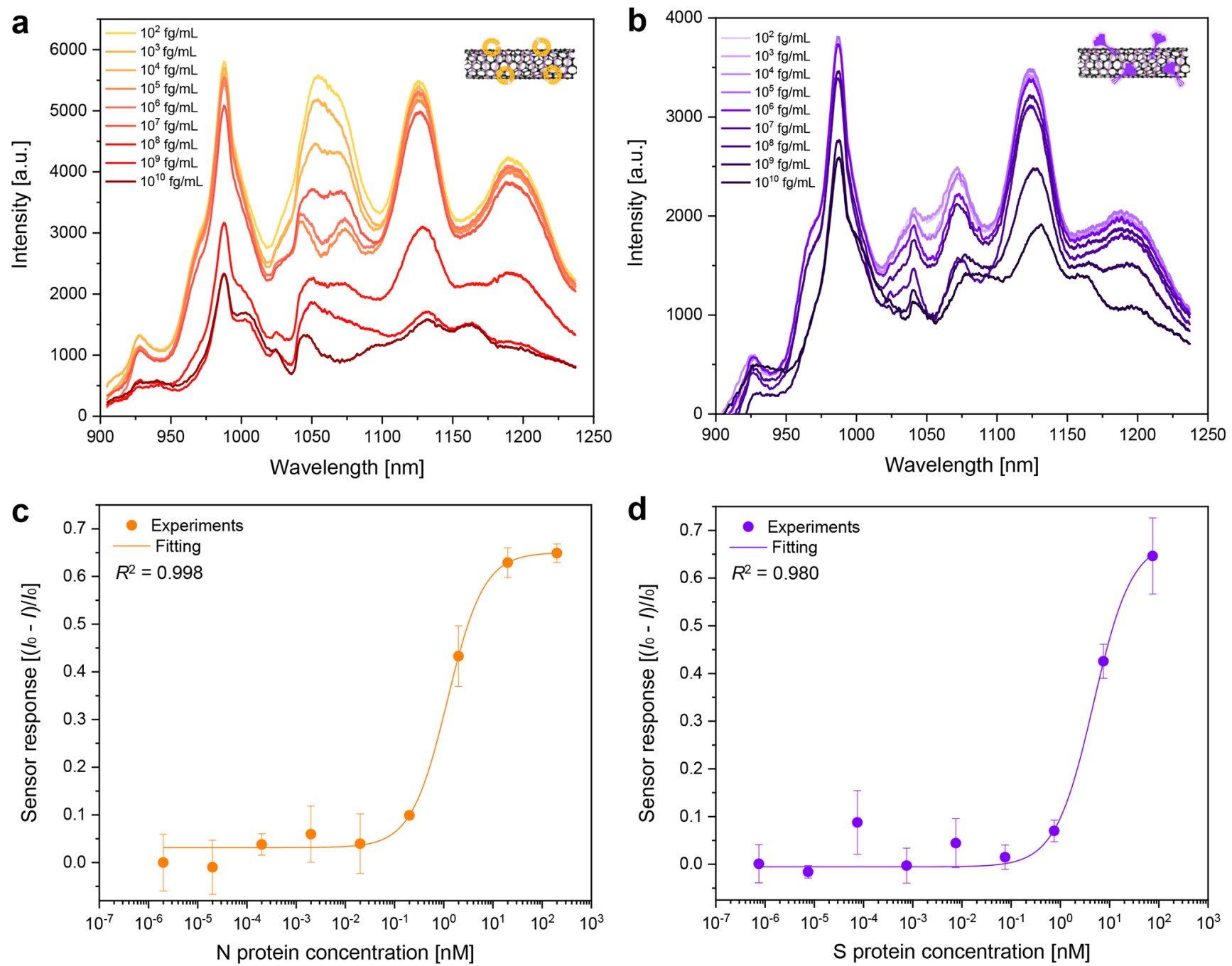

Figure 3. Limit of detection (LOD) characterization of two SARS-CoV-2 protein nanosensors for $\mathrm{N}$ and S. Fluorescent emission spectra of (a) nanosensor ii and (b) nanosensor vi on a wide concentration range $\left(10^{2}-10^{10} \mathrm{fg} / \mathrm{mL}\right)$ of $\mathrm{N}$ and $\mathrm{S}$ proteins, respectively. Integrated fluorescence intensity at reaction time $=60 \mathrm{~min}$ for (c) nanosensor ii and (d) nanosensor vi with cooperative binding model fitting to quantify nanosensor kinetic parameters. Fitting parameters are $\alpha=61.91 \pm 1.267$ and $0.683 \pm 0.092, \beta=3.14 \pm 0.852$ and $-0.005 \pm 0.009, K_{d}=0.840 \pm 0.121$ and $0.213 \pm 0.071 \mathrm{nM}$, and $n=1.176 \pm 0.101$ and $1.120 \pm 0.197$ for $\mathrm{N}$ and $\mathrm{S}$ proteins, respectively. Data are mean (circle) $\pm \sigma$ (error bar), with replicates $n=3$.

maintained for $60 \mathrm{~min}$, and the response of nanosensor vi decreased after the first peak response of the $S$ protein.

Real-time nIR sensor responses were measured using a wide range of concentrations from the $\mathrm{fM}$ to $\mathrm{nM}$ level of $\mathrm{N}$ and $\mathrm{S}$ proteins (Figure 3). Upon $\mathrm{N}$ and $\mathrm{S}$ protein addition, nanosensor ii (Figure 3a) and nanosensor vi (Figure 3b) show an instantaneous and continuous decrease in nIR signal on the order of 5-70\%, depending on protein concentrations. Nanosensor kinetic parameters were determined by fitting the maximum sensor response for $60 \mathrm{~min}$ to each analyte concentration series using the cooperative binding model of the Hill equation. ${ }^{35}$ For a first-order reversible reaction, the relationship between the analyte (A) and available docking sites $(\theta)$ for viral proteins can be described as follows.

$$
A+\theta \rightleftarrows A \theta
$$

where $A \theta$ is the surface concentration of analyte-bound sensor sites. The resulting equilibrium for this reaction is

$$
K_{\mathrm{A}}=\frac{[\mathrm{A} \theta]}{[\mathrm{A}][\theta]}
$$

Assuming that the sensor response is proportional to the $A \theta /$ $\theta_{\text {tot }}$ ratio, it is found that

$$
\frac{I_{0}-I}{I_{0}}=\alpha \frac{[\mathrm{A} \theta]}{\left[\theta_{\mathrm{tot}}\right]}+\beta=\alpha \frac{\left([\mathrm{A}] K_{\mathrm{A}}\right)^{n}}{\left([\mathrm{~A}] K_{\mathrm{A}}\right)^{n}+1}+\beta
$$

with the total concentration of available recognition sites on the sensor a constant of $[\theta]_{\text {tot }}$ and the parameter $\mathrm{n}$ for the analyte cooperativity. Fitting the data in Figure 3a,b with eq 3 $\left(R^{2}=0.998\right.$ and 0.980$)$ results in a proportionality factor $\alpha=$ 61.91 and 0.683 , with $\beta=3.14$ and $-0.005, K_{\mathrm{d}}=1 / K_{\mathrm{A}}=0.840$ and $0.213 \mathrm{nM}$, and $n=1.176$ and 1.120 for $\mathrm{N}$ and $\mathrm{S}$ proteins respectively, indicating positive cooperativity in good agreement with previous work $(n>1)$ (Figure $3 c, d) .{ }^{19}$ The $K_{d}$ value of $\mathrm{N}$ and $\mathrm{S}$ protein nanosensors are lower than previously reported CoPhMoRe sensing, which suggests the influence of the larger molecular size of viral proteins, with more binding 


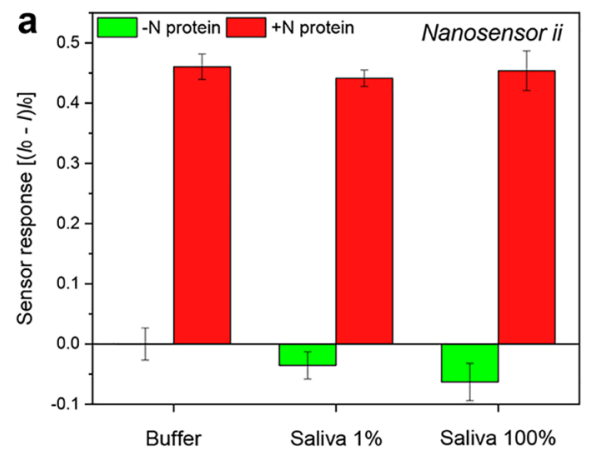

C

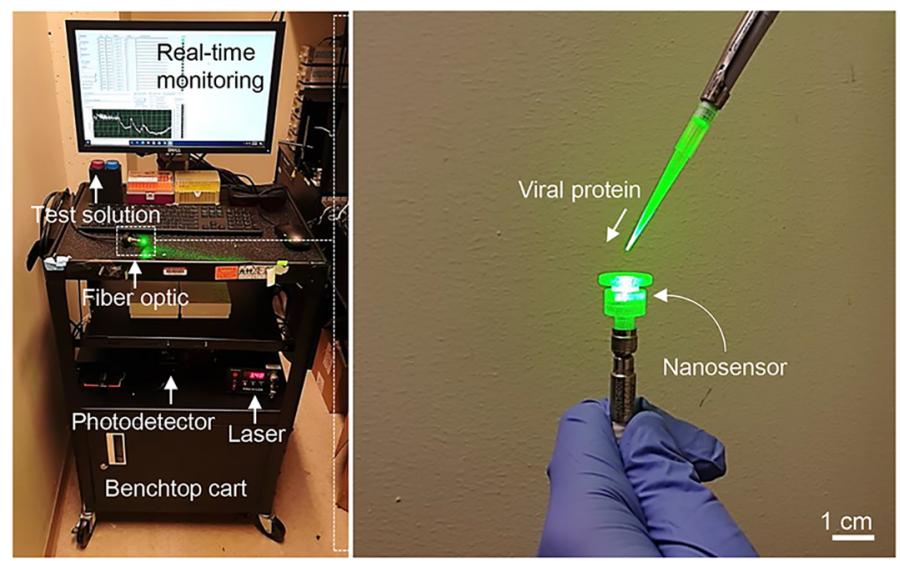

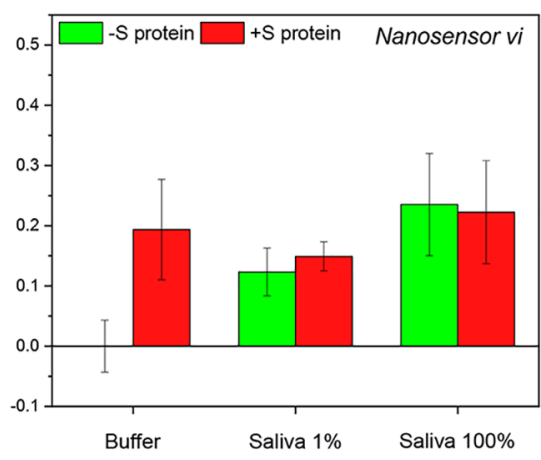

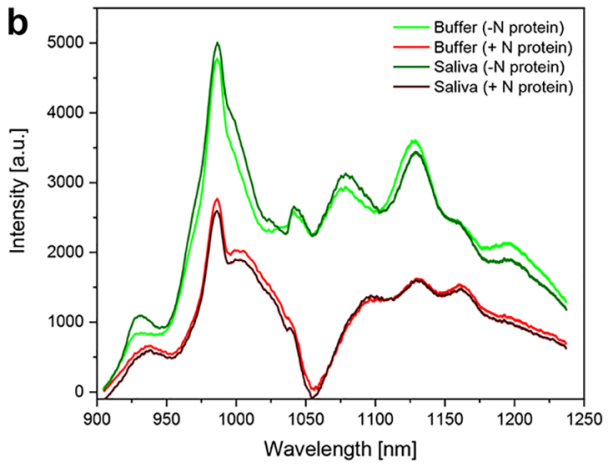

d

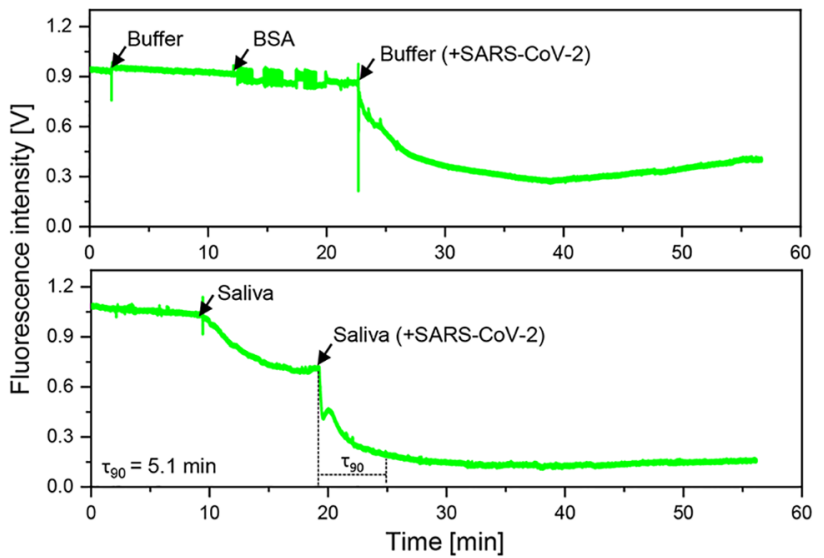

Figure 4. Lab-on-Fiber on-site monitoring system of SARS-CoV-2 proteins based on nanosensor development in this work. (a) Normalized sensor responses of (left) nanosensor ii and (right) nanosensor vi to $\mathrm{N}$ and S proteins in buffer, saliva $1 \%$, and saliva $100 \%$. The SWCNT and protein concentrations were $0.5 \mathrm{mg} / \mathrm{L}$ and $10 \mu \mathrm{g} / \mathrm{mL}$, respectively. The data represent the mean value of $n=3$ replicates. (c) Photo images of the fully integrated fiber-optic benchtop instrument with benchtop mobile cart. The sensor response to viral protein dropping was real-time measured under $561 \mathrm{~nm}$ laser excitation. (d) Real-time fiber optic monitoring of SARS-CoV-2 viral protein using CoPhMoRe nanosensor $(10 \mu \mathrm{g} / \mathrm{mL} \mathrm{N} \mathrm{protein,} 5$ $\mu \mathrm{L}$ droplet). Top: protein in buffer solution. Bottom: protein in saliva $100 \%$.

sites involved, and hence polyvalent interactions. The limit of detection value in this mode is $49 \mathrm{fM}$ and $350 \mathrm{pM}$ for $\mathrm{N}$ and $\mathrm{S}$ proteins, respectively; this value was calculated by adding the nanosensor response from the addition of only buffer as the noise level to three times of the signal.

Our SARS-CoV-2 nanosensor compatibility in biofluids was assessed by testing the response to viral proteins in 1 and $100 \%$ human saliva (details in Table S1). For the $\mathrm{N}$ protein nanosensor, small sensor responses with 3.5 and $6.3 \%$ intensity change were observed with 1 and $100 \%$ saliva, respectively (left, Figure 4a). However, significantly larger responses to $\mathrm{N}$ protein in $100 \%$ saliva were observed with $45.4 \%$ change, demonstrating that $\mathrm{N}$ protein detection appears to be independent of background saliva effects. SARS-CoV-2 patients show $\mathrm{N}$ protein concentration range from 10 to $10^{4}$ $\mathrm{pg} / \mathrm{mL}$ in their saliva during symptoms of day $1-7 . .^{36}$ Since detecting range of our nanosensor vi (LOD value of $2.4 \mathrm{pg}$ / $\mathrm{mL}$ ) sufficiently covers this clinical range, we expect that the CoPhMoRe nanosensor can diagnose the positive cases with a real saliva sample. For the $S$ protein nanosensor, on the other hand, the sensor responses to the analyte were clearly diminished in saliva conditions with almost similar changes for the control $-S$ protein saliva and $+S$ protein saliva samples (right, Figure 4a). The attenuation of the highly glycosylated $S$ protein nanosensor response seems to arise from the decreased baseline of the fluorescence with saliva background. ${ }^{37,38}$ One hypothesis for future exploration is that the salivary glycoprotein can adsorb onto the $S$ protein nanosensor surface and reduce the baseline fluorescence intensity and block viral protein binding. The $\mathrm{N}$ protein, on the other hand, is phosphorylated, and the analyte-nanosensor interaction is not affected by glycoproteins present in saliva. ${ }^{39}$ The nIR fluorescence spectra demonstrate that our $\mathrm{N}$ protein nanosensor shows almost identical responses in buffer and the $100 \%$ human saliva condition (Figure $4 \mathrm{~b}$ ). This suggests that the PEG-phospholipid nanosensor passivation, built into this construct, enables at least partial reduction of nanosensor biofouling. $^{21}$

To demonstrate a form of the sensor compatible with diagnosis in a non-laboratory setting, we interfaced the nanosensors in this work into a Lab-on-Fiber system using a fiber-optic-based benchtop instrument to produce a sensor optode. All components, including the optode fiber, laser, nanosensors, nIR detectors, monitor, controller, and test solutions, can be compactly integrated onto a mobile cart (for example, left, Figure 4c). The optode fiber is flexible, lightweight, and robust enough such that the tip can be applied to samples for diagnosis with an ease not found with conventional analytical tools. ${ }^{40}$ We designed and fabricated 3D miniaturized sensor tips as interfaces that hold the SARSCoV-2 nanosensor media and viral protein components stably onto the fiber optics using 3D printing and a developed template (Objet30 Prime, Stratasys Ltd). The sensing tip is engineered at a high resolution ( $\mathrm{mm}$-scale) in a specific $3 \mathrm{D}$ 


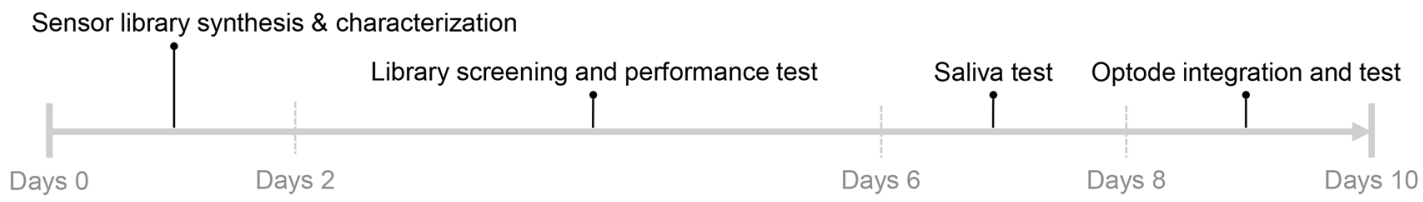

b From Unknown Target to On-Site Medical Assay

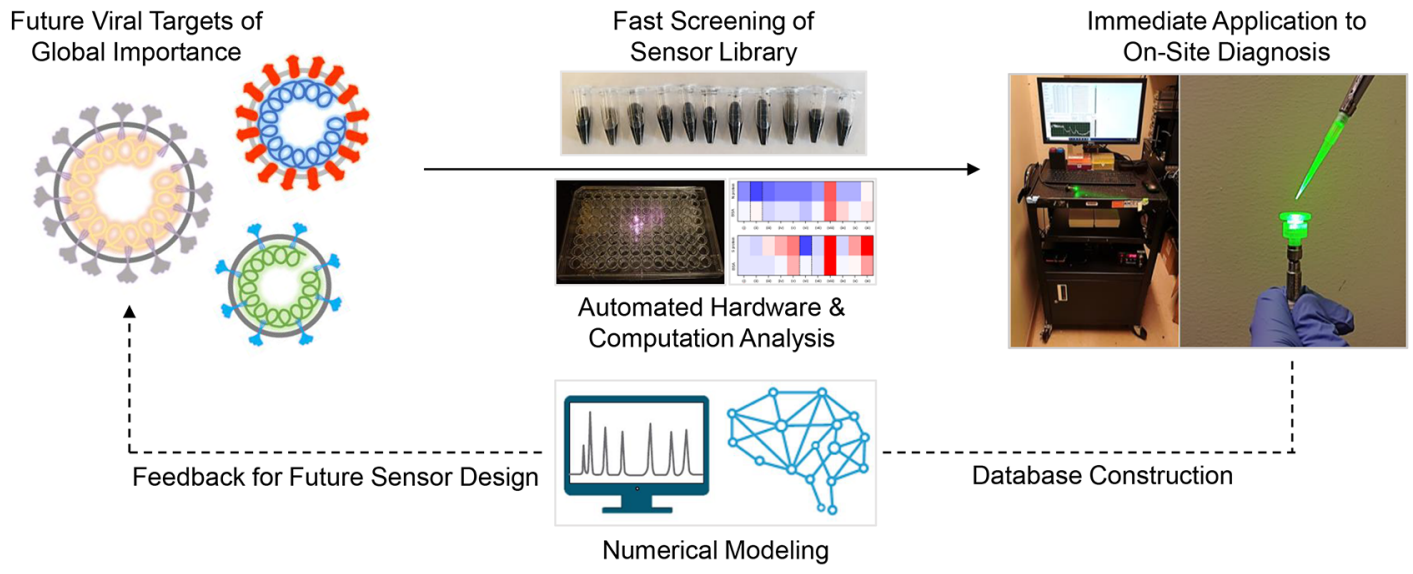

Figure 5. Potential workflow for CoPhMoRe-based viral detection for a hypothetical future pandemic. (a) To estimate the labor scheduling for such a workflow, the timeline for the SARS-CoV-2 protein sensor development of this work is presented. Approximately 10 days of laboratory effort from two researchers with approximately $4 \mathrm{~h}$ per day completed the development. This includes experiments with associated waiting and analysis time, excluding reagent delivery time. (b) Schematic of an accelerated point-of-care sensor development with continual feedback to address emerging viral targets in the future.

architecture such that viral proteins can be sensitively detected even with low volumes of biofluid extraction (currently $<10$ $\mu \mathrm{L}$ ). The printed $3 \mathrm{D}$ sensing tip was successfully integrated with the optode fiber by screwing onto an SMA (SubMiniature version A) connector and supported by an $8 \mathrm{~mm}$ cover glass slide for the Lab-on-Fiber SARS-CoV-2 diagnosis system (left, Figure $4 \mathrm{c}$ ). Figure $4 \mathrm{~d}$ shows the real-time fluorescence response of the completed, fully-integrated optode fiber to SARS-CoV-2 N protein in buffer (top graph) and in $100 \%$ human saliva condition (bottom graph). A $5 \mu \mathrm{L}$ viral protein solution was directly dropped onto the $3 \mathrm{D}$ printed sensing tip of the optode fiber, and the resulting sensor response was directly measured using the benchtop instrument. The optode fiber itself generates no response to pure buffer spiked with BSA but the expected rapid and sizable turn-off response to $\mathrm{N}$ protein in buffer with a $71.3 \%$ change in intensity. For the $100 \%$ saliva condition, the optode fiber appears to show a background quenching response to pure saliva (labeled -SARS-CoV-2) with a $30 \%$ change, the origins of which are unclear at this time. However, saliva plus analyte (labeled +SARS-CoV-2) demonstrates a response of $85.7 \%$, easily above the background and statistically significant. A response time $\left(\tau_{90}\right)$ of $5.1 \mathrm{~min}$ was achieved based on the time to reach $90 \%$ of the nIR level at infinity. Overall, the platform appears rapid enough for SARS-CoV-2 detection with small biofluid volume additions and short response time such that nonlaboratory operation is possible.

We are also interested in the development timeline and workflow necessary to generate a sensor for viral detection, starting from identification of the new viral target itself to deployable hardware ready for screening of the population.
The CoPhMoRe technique seems to allow for rapid development, with libraries that can be screened at an accelerated pace to find a sensor optimum for a given viral target. Figure 5a shows the development timeline for this work, following the experimental history of the project. We synthesized the whole CoPhMoRe library, performed characterization of the corona phases, screened against viral biomarkers, and evaluated the sensor performance for nanosensors for $\mathrm{N}$ and $\mathrm{S}$ protein targets separately within just 6 days of two researchers working $4 \mathrm{~h}$ per day.

In addition, these optimized nanosensor candidates could be efficiently integrated into a modular optode fiber-optic setup and tested against the relevant biofluid (saliva) within 4 days. This sensor development depends on the design and selection of the proper corona phase. Thus, in cases where no commercial polymer or chemistry shows satisfactory sensitivity and/or selectivity toward the target analytes, the development timeline may be extended. We argue that it is a unique feature of this type of molecular recognition scheme making rapid design and testing possible, unhindered by the development time and supply chain requirements of a conventional antibody or enzymatic receptor. CoPhMoRe is also compatible with fully automated fluorescence screening hardware that connects seamlessly to a benchtop optics platform. This rapid development workflow holds several potential advantages for future viral targets. Based on this, we expect that our CoPhMoRe platform can be readily applied to a potential future pandemic with unknown viruses (Figure $5 b$ ). If a new virus target begins to circulate, this workflow can generate a corona interface library and synthesize recognition candidates within a few days. Computational analysis can be used to 
predict selectivity and sensitivity performance in advance of experimental validation. Then, the optimized nanosensor with selective recognition for the unknown viral target can be interfaced directly to the existing benchtop platform shown in Figure 4c. Thus, the sensor produced from the CoPhMoRebased sensor screening platform is potentially ready for field deployment in advance of a future pandemic. In addition, based on the sensing and diagnosis data, we can also construct the database of CoPhMoRe sensor library onto a variety of viruses. In this way, the workflow allows for a potential feedback loop for continual sensor development targeting new, emerging viruses, leveraging numerical modeling.

\section{CONCLUSIONS}

In summary, we have developed complexes of fluorescent SWCNTs suspended using PEGylated lipid heteropolymers that selectively recognize the $\mathrm{N}$ and $\mathrm{S}$ proteins of SARS-CoV-2 virus. These synthetic, nonbiological recognition sites provide an alternative for conventional SARS-CoV-2 detection methods, which suffer from major drawbacks, including the need for special equipment and trained personnel, complex sample processing, long process time, and poor stability. In contrast, the SWCNT-based nanosensors developed in this work apparently overcome these limitations by demonstrating stable and reproducible constructs that enable rapid and antibody-free detection of SARS-CoV-2 viral proteins with high sensitivity. Furthermore, the $\mathrm{N}$ protein sensor is shown to maintain functionality even in $100 \%$ human saliva. Future work will focus on incorporating the nanosensors into systems amenable to point-of-care applications, enabling rapid and label-free detection of the SARS-CoV-2 virus and its biomarkers. Our work also paves the way for the rapid development of the synthetic molecular recognition necessary for viral protein sensor development of future targets.

\section{EXPERIMENTAL SECTION}

Materials. Raw single-walled carbon nanotubes (SWCNTs) produced by HiPCO process were purchased from NanoIntegris and used without further processing (Batch\# HR27-104). PEG-phospholipids were purchased from Avanti Polar Lipids, Inc. All other chemicals were purchased from MilliporeSigma.

Nanosensor Synthesis and Characterizations. In $1 \mathrm{~mL}$ of DI water, $1 \mathrm{mg}$ (1 equiv) of HiPCO SWCNT and $1 \mathrm{mg}$ (1 equiv) of PEG-phospholipid were mixed. The mixture was ultrasonicated using a $1 / 8^{\prime \prime}$ probe (Cole-Parmer) at a power of $10 \mathrm{~W}$ for $30 \mathrm{~min}$ (QSonica). The resulting suspension was benchtop-centrifuged twice at $30300 \mathrm{RCF}$ for $1 \mathrm{~h}$ (Eppendorf centrifuge $5430 \mathrm{R})$. The top $80 \%$ of the suspension was reserved for further use, while the remaining $20 \%$ was discarded. UV-vis-nIR absorption spectroscopy (Agilent Technologies, Cary 5000) was used to confirm successful suspensions and obtain the mass concentration of the nanoparticles using an extinction coefficient of $\varepsilon_{632}=0.036$ $\mathrm{mg} /(\mathrm{L} \cdot \mathrm{cm}) .{ }^{41}$ The accessible surface area of the PEGphospholipid-wrapped SWCNT was measured using the molecular probe adsorption technique. ${ }^{32}$ Fluorescence emission $(510-560 \mathrm{~nm})$ intensity of riboflavin was measured using a Thermo Varioskan plate, with excitation at $460 \mathrm{~nm}$. Deflections of the riboflavin fluorescence were taken in the presence of nanosensor suspensions with an SWCNT concentration of $10 \mathrm{mg} / \mathrm{L}$.
nIR Signal Measurements. High-throughput screening of the nanosensor library against the viral proteins was performed using a customized nIR microscope, which consists of a ZEISS Axio Vision inverted microscope body with a $20 \times$ objective, coupled to an Acton SP2500 spectrometer and liquid nitrogencooled InGaAs 1D detector (Princeton Instruments). In a 96well plate, one PEG-phospholipid/SWCNT sensor $(0.5 \mathrm{mg} / \mathrm{L})$ and one viral protein ( $\mathrm{N}$ or S protein, $10 \mu \mathrm{g} / \mathrm{mL}$ ) were mixed in a final volume of $200 \mu \mathrm{L}$ in $\mathrm{N}$ protein buffer $(15 \mathrm{mM}$ $\mathrm{Na}_{2} \mathrm{HPO}_{4}, 5 \mathrm{mM} \mathrm{NaH} \mathrm{PO}_{4}, 0.25 \mathrm{M} \mathrm{NaCl}, \mathrm{pH} \mathrm{7.5)}$ and $\mathrm{S}$ protein buffer ( $2 \mathrm{mM}$ Tris, $200 \mathrm{mM} \mathrm{NaCl}, \mathrm{pH} 8.0$ ) and incubated for $1 \mathrm{~h}$ in each well. The samples were then illuminated by a $150 \mathrm{~mW} 785 \mathrm{~nm}$ photodiode laser (B\&W Tek Inc.), and fluorescence emission spectra were collected from 950 to $1250 \mathrm{~nm}$. Peak position and intensities of each sensorviral proteins pair were compared to a nanosensor/buffer and nanosensor/BSA control to calculate the selective sensor responses. The most promising candidates were identified and studied further. Proteins and saliva were sourced and reconstituted as listed in Table S1. Briefly, 1 and 100\% saliva are calculated from the saliva concentration of whole analyte solution, including viral proteins.

Optode Fiber Measurements. Sensors were excited with $561 \mathrm{~nm}$ (MGL-FN-561 200mW, Opto Engine LLC) or 785 nm (MDL-III-785 500mW, Opto Engine LLC). The laser light propagates through fiber-optic reflection/backscatter probe bundles (RP29, Thorlabs) to the samples, and the fluorescence light propagates through the fiber to InGaAs-amplified photodetector (PDF10C, Thorlabs). The fiber optic probe consists of six fibers around one fiber configuration, where the central fiber provides the light delivery to the PEGphospholipid/SWCNT nanosensor. The surrounding six fibers collect the near-infrared fluorescence light from the nanosensor. To reduce laser scattering and autofluorescence at hydrogel, $900 \mathrm{~nm}$ short-pass filter and $900 \mathrm{~nm}$ long-pass filter were inserted at the laser and photodetector, respectively. A focusing lens with a focal length of $30 \mathrm{~mm}$ is placed to efficiently collect fluorescence signals at $0.5 \mathrm{~mm}$ diameter active area of the photodetector. All of the components of the instrument are loaded on a mobile cart (15Y320, Grainger, size: depth $18^{\prime \prime}$, width $24^{\prime \prime}$, height $\left.26-42^{\prime \prime}\right)$. For the real-time signal measurement of SARS-CoV-2, $5 \mu \mathrm{L}$ buffer, BSA $(10 \mu \mathrm{g} /$ $\mathrm{mL})$, and $\mathrm{N}$ protein $(10 \mu \mathrm{g} / \mathrm{mL})$ were added in series, and fluorescence signals were measured for $30 \mathrm{~min}$. 3D sensing tips were fabricated using a 3D printer (Objet30 Prime, Stratasys Ltd.). The print was executed using "high quality" settings and VeroClear (PN: OBJ-04055, Stratasys) material with a minimum layer thickness of $16 \mu \mathrm{m}$. The prints were washed from the support material using an electric power washer (supplied by Stratasys). The resolution of $3 \mathrm{D}$ printer is $X$-axis: $600 \mathrm{dpi}$; $Y$-axis: $600 \mathrm{dpi}$; $Z$-axis: $1600 \mathrm{dpi}$; and accuracy is 0.1 $\mathrm{mm}\left(0.0039^{\prime \prime}\right)$.

\section{ASSOCIATED CONTENT}

\section{Supporting Information}

The Supporting Information is available free of charge at https://pubs.acs.org/doi/10.1021/acs.analchem.1c02889.

Nanotube surface coverage characterization; molecular probe adsorption curve with slope inversely proportional to the accessible surface area; fluorescent emission spectra of nanosensor ii and nanosensor vi on control buffer, BSA, and viral protein; fluorescent emission 
spectra variation of nanosensors as a function of time; and proteins and saliva specifications used for the study (PDF)

\section{AUTHOR INFORMATION}

\section{Corresponding Author}

Michael S. Strano - Department of Chemical Engineering, Massachusetts Institute of Technology, Cambridge, Massachusetts 02139, United States; (1) orcid.org/00000003-2944-808X; Email: strano@mit.edu

\section{Authors}

Soo-Yeon Cho - Department of Chemical Engineering, Massachusetts Institute of Technology, Cambridge, Massachusetts 02139, United States; 이이.org/00000001-6294-1154

Xiaojia Jin - Department of Chemical Engineering, Massachusetts Institute of Technology, Cambridge, Massachusetts 02139, United States

Xun Gong - Department of Chemical Engineering, Massachusetts Institute of Technology, Cambridge, Massachusetts 02139, United States; O orcid.org/00000003-4168-2768

Sungyun Yang - Department of Chemical Engineering, Massachusetts Institute of Technology, Cambridge, Massachusetts 02139, United States

Jianqiao Cui - Department of Chemical Engineering, Massachusetts Institute of Technology, Cambridge, Massachusetts 02139, United States

Complete contact information is available at: https://pubs.acs.org/10.1021/acs.analchem.1c02889

\section{Author Contributions}

S.-Y.C. and X.J. contributed equally to the technical portion of this work. The manuscript was written through contributions of all authors. All authors have given approval to the final version of the manuscript.

\section{Notes}

The authors declare no competing financial interest.

\section{ACKNOWLEDGMENTS}

The authors are grateful for helpful discussions with Dr. Roya Khosravi-Far, InnoTech Precision Medicine, Inc. SPIKE (Stable) protein was a generous gift from Dr. Jason McLellan (Department of Molecular Biosciences, University of Texas, Austin, TX 78712). Financial support for this work was from the National Institute of Health (NIH) Rapid Acceleration of Diagnostics (RADX) 1R42DE030829 to Dr. Roya KhosraviFar.

\section{REFERENCES}

(1) Kronbichler, A.; Kresse, D.; Yoon, S.; Lee, K. H.; Effenberger, M.; Shin, J. I. Int. J. Infect. Dis. 2020, 98, 180-186.

(2) Udugama, B.; Kadhiresan, P.; Kozlowski, H. N.; Malekjahani, A.; Osborne, M.; Li, V. Y. C.; Chen, H.; Mubareka, S.; Gubbay, J. B.; Chan, W. C. W. ACS Nano 2020, 14, 3822-3835.

(3) Pokhrel, P.; Hu, C.; Mao, H. ACS Sens. 2020, 5, 2283-2296.

(4) Esbin, M. N.; Whitney, O. N.; Chong, S.; Maurer, A.; Darzacq, X.; Tjian, R. RNA 2020, 26, 771-783.

(5) Mio, C.; Cifù, A.; Marzinotto, S.; Bergamin, N.; Caldana, C.; Cattarossi, S.; Cmet, S.; Cussigh, A.; Martinella, R.; Zucco, J.; Verardo, R.; Schneider, C.; Marcon, B.; Zampieri, S.; Pipan, C.; Curcio, F. Dis. Markers 2020, 2020, No. 8869424.
(6) McMinn, S.; Carlsen, A.; Jaspers, B.; Talbot, R.; Adeline, S. In Large Texas Cities, Access To Coronavirus Testing May Depend On Where You Live. https://www.npr.org/sections/health-shots/2020/ 05/27/862215848/across-texas-black-and-hispanic-neighborhoodshavefewer-coronavirus-testing-sit (accessed June 17, 2021).

(7) Kim, S.; Hao, Y.; Miller, E. A.; Tay, D. M. Y.; Yee, E.; Kongsuphol, P.; Jia, H.; McBee, M.; Preiser, P. R.; Sikes, H. D. ACS Sens. 2021, 6, 1891-1898.

(8) EUA, Authorized Serology Test Performance. https://www.fda. gov/medical-devices/coronavirus-disease-2019-covid-19-emergencyuse-authorizations-medical-devices/eua-authorized-serology-testperformance (accessed on June 17, 2021).

(9) Whitman, J. D.; Hiatt, J.; Mowery, C. T.; Shy, B. R.; Yu, R.; Yamamoto, T. N.; Rathore, U.; Goldgof, G. M.; Whitty, C.; Woo, J. M.; et al. Nat. Biotechnol. 2020, 38, 1174-1183.

(10) Vandenberg, O.; Martiny, D.; Rochas, O.; van Belkum, A.; Kozlakidis, Z. Nat. Rev. Microbiol. 2021, 19, 171-183.

(11) American Society for Microbiology, Laboratory Supply Shortages Are Impacting COVID-19 and Non-COVID Diagnostic Testing. https://asm.org/Articles/2020/September/LaboratorySupply-Shortages-Are-Impacting-COVID-19 (accessed on June 18, 2021).

(12) Seo, G.; Lee, G.; Kim, M. J.; Baek, S.-H.; Choi, M.; Ku, K. B.; Lee, C.-S.; Jun, S.; Park, D.; Kim, H. G.; Kim, S.-J.; Lee, J.-O.; Kim, B. T.; Park, E. C.; Kim, S. I. ACS Nano 2020, 14, 5135-5142.

(13) Shao, W.; Shurin, M. R.; Wheeler, S. E.; He, X.; Star, A. ACS Appl. Mater. Interfaces 2021, 13, 10321-10327.

(14) Zhang, X.; Qi, Q.; Jing, Q.; Ao, S.; Zhang, Z.; Ding, M.; Wu, M.; Liu, K.; Wang, W.; Ling, Y.; Zhang, Z.; Fu, W. ElecTrical Probing of COVID-19 Spike Protein Receptor Binding Domain via A Graphene Field-Effect Transistor, arXiv:2003.12529. arXiv.org ePrint archive. https://arxiv.org/abs/2003.12529 (submitted Mar 27, 2020).

(15) Guo, K.; Wustoni, S.; Koklu, A.; Díaz-Galicia, E.; Moser, M.; Hama, A.; Alqahtani, A. A.; Ahmad, A. N.; Alhamlan, F. S.; Shuaib, M.; Pain, A.; McCulloch, I.; Arold, S. T.; Grünberg, R.; Inal, S. Nat. Biomed. Eng. 2021, 5, 666-677.

(16) Mahari, S.; Roberts, A.; Shahdeo, D.; Gandhi, S. eCovSensUltrasensitive Novel In-House Built Printed Circuit Board Based Electrochemical Device for Rapid Detection of nCovid-19 antigen, a spike protein domain 1 of SARS-CoV-2 bioRxiv 2020, DOI: 10.1101/ 2020.04.24.059204.

(17) Beduk, T.; Beduk, D.; Filho, J. I. D. O.; Zihnioglu, F.; Cicek, C.; Sertoz, R.; Arda, B.; Goksel, T.; Turhan, K.; Salama, K. N.; Timur, S. Anal. Chem. 2021, 93, 8585-8594.

(18) Qiu, G.; Gai, Z.; Tao, Y.; Schmitt, J.; Kullak-Ublick, G. A.; Wang, J. ACS Nano 2020, 14, 5268-5277.

(19) Ahmadivand, A.; Gerislioglu, B.; Ramezani, Z.; Kaushik, A.; Manickam, P.; Ghoreishi, S. A. Biosens. Bioelectron. 2021, 177, No. 112971.

(20) Chen, H.; Park, S.-G.; Choi, N.; Kwon, H.-J.; Kang, T.; Lee, M.K.; Choo, J. ACS Sens. 2021, 6, 2378-2385.

(21) Pinals, R. L.; Ledesma, F.; Yang, D.; Navarro, N.; Jeong, S.; Pak, J. E.; Kuo, L.; Chuang, Y.-C.; Cheng, Y.-W.; Sun, H.-Y.; Landry, M. P. Nano Lett. 2021, 21, 2272-2280.

(22) Chen, R.; Ren, C.; Liu, M.; Ge, X.; Qu, M.; Zhou, X.; Liang, M.; Liu, Y.; Li, F. ACS Nano 2021, 15, 8996-9004.

(23) Moitra, P.; Alafeef, M.; Dighe, K.; Frieman, M. B.; Pan, D. ACS Nano 2020, 14, 7617-7627.

(24) Shan, B.; Broza, Y. Y.; Li, W.; Wang, Y.; Wu, S.; Liu, Z.; Wang, J.; Gui, S.; Wang, L.; Zhang, Z.; Liu, W.; Zhou, S.; Jin, W.; Zhang, Q.; Hu, D.; Lin, L.; Zhang, Q.; Li, W.; Wang, J.; Liu, H.; Pan, Y.; Haick, H. ACS Nano 2020, 14, 12125-12132.

(25) Du, L.; He, Y.; Zhou, Y.; Liu, S.; Zheng, B.-J.; Jiang, S. Nat. Rev. Microbiol. 2009, 7, 226-236.

(26) Lan, J.; Ge, J.; Yu, J.; Shan, S.; Zhou, H.; Fan, S.; Zhang, Q.; Shi, X.; Wang, Q.; Zhang, L.; Wang, X. Nature 2020, 581, 215-220. 
(27) Jia, H.; Zhang, A.; Yang, Y.; Cui, Y.; Xu, J.; Jiang, H.; Tao, S.; Zhang, D.; Zeng, H.; Hou, Z.; Feng, J. Lab Chip 2021, 21, 23982406.

(28) Saerens, D.; Huang, L.; Bonroy, K.; Muyldermans, S. Sensors 2008, 8, 4669-4686.

(29) Peluso, P.; Wilson, D. S.; Do, D.; Tran, H.; Venkatasubbaiah, M.; Quincy, D.; Heidecker, B.; Poindexter, K.; Tolani, N.; Phelan, M.; Witte, K.; Jung, L. S.; Wagner, P.; Nock, S. Anal. Biochem. 2003, 312, $113-124$.

(30) Charter, N. W.; Horecka, J.; Loh, C. Y.; Doan, A.; Wehrman,

T.; Olson, K. R. Methods Mol. Biol. 2009, 536, 395-405.

(31) Bisker, G.; Dong, J.; Park, H. D.; Iverson, N. M.; Ahn, J.; Nelson, J. T.; Landry, M. P.; Kruss, S.; Strano, M. S. Nat. Commun. 2016, 7, No. 10241.

(32) Park, M.; Salem, D. P.; Parviz, D.; Gong, X.; Silmore, K. S.; Lew, T. T. S.; Khong, D. T.; Ang, M. C.-Y.; Kwak, S. Y.; Chan-Park, M. B.; Strano, M. S. Nano Lett. 2019, 19, 7712-7724.

(33) Zhang, J. Q.; Landry, M. P.; Barone, P. W.; Kim, J. H.; Lin, S. C.; Ulissi, Z. W.; Lin, D. H.; Mu, B.; Boghossian, A. A.; Hilmer, A. J.; Rwei, A.; Hinckley, A. C.; Kruss, S.; Shandell, M. A.; Nair, N.; Blake, S.; Sen, F.; Sen, S.; Croy, R. G.; Li, D.; Yum, K.; Ahn, J.-H.; Jin, H.; Heller, D. A.; Essigmann, J. M.; Blankschtein, D.; Strano, M. S. Nat. Nanotechnol. 2013, 8, 959-968.

(34) Lee, M. A.; Wang, S.; Jin, X.; Bakh, N. A.; Nguyen, F. T.; Dong, J.; Silmore, K. S.; Gong, X.; Pham, C.; Jones, K. K.; Muthupalani, S.; Bisker, G.; Son, M.; Strano, M. S. Adv. Healthcare Mater. 2020, 9, No. 2000429.

(35) Kruss, S.; Landry, M. P.; Vander Ende, E.; Lima, B. M. A.; Reuel, N. F.; Zhang, J.; Nelson, J.; Mu, B.; Hilmer, A.; Strano, M. J. Am. Chem. Soc. 2014, 136, 713-724.

(36) Shan, D.; Johnson, J. M.; Fernandes, S. C.; Suib, H.; Hwang, S.; Wuelfing, D.; Mendes, M.; Holdridge, M.; Burke, E. M.; Beauregard, K.; Zhang, Y.; Cleary, M.; Xu, S.; Yao, X.; Patel, P. P.; Plavina, T.; Wilson, D. H.; Chang, L.; Kaiser, K. M.; Nattermann, J.; Schmidt, S. V.; Latz, E.; Hrusovsky, K.; Mattoon, D.; Ball, A. J. Nat. Commun. 2021, 12, No. 1931.

(37) Ramírez Hernández, E.; Hernández-Zimbrón, L. F.; Zúñiga, N. M.; Leal-García, J. J.; Hernández, V. I.; Ucharima-Corona, L. E.; Campos, E. P.; Zenteno, E. Viral Immunol. 2021, 34, 165-173.

(38) Watanabe, Y.; Allen, J. D.; Wrapp, D.; McLellan, J. S.; Crispin, M. Science 2020, 369, 330-333.

(39) Bouhaddou, M.; Memon, D.; Meyer, B.; White, K. M.; Rezelj, V. V.; Correa Marrero, M.; Polacco, B. J.; Melnyk, J. E.; Ulferts, S.; Kaake, R. M.; Batra, J.; Richards, A. L.; Stevenson, E.; Gordon, D. E.; Rojc, A.; Obernier, K.; Fabius, J. M.; Soucheray, M.; Miorin, L.; Moreno, E.; Koh, C.; Tran, Q. D.; Hardy, A.; Robinot, R.; Vallet, T.; NilssonPayant, B. E.; Hernandez-Armenta, C.; Dunham, A.; Weigang, S.; Knerr, J.; Modak, M.; Quintero, D.; Zhou, Y.; Dugourd, A.; Valdeolivas, A.; Patil, T.; Li, Q.; Hüttenhain, R.; Cakir, M.; Muralidharan, M.; Kim, M.; Jang, G.; Tutuncuoglu, B.; Hiatt, J.; Guo, J. Z.; Xu, J.; Bouhaddou, S.; Mathy, C. J. P.; Gaulton, A.; Manners, E. J.; Felix, E.; Shi, Y.; Goff, M.; Lim, J. K.; McBride, T.; O’Neal, M. C.; Cai, Y.; Chang, J. C. J.; Broadhurst, D. J.; Klippsten, S.; De Wit, E.; Leach, A. R.; Kortemme, T.; Shoichet, B.; Ott, M.; SaezRodriguez, J.; tenOever, B. R.; Mullins, R. D.; Fischer, E. R.; Kochs, G.; Grosse, R.; García-Sastre, A.; Vignuzzi, M.; Johnson, J. R.; Shokat, K. M.; Swaney, D. L.; Beltrao, P.; Krogan, N. J. Cell 2020, $182,685-712$.

(40) Kozawa, D.; Cho, S.-Y.; Gong, X.; Nguyen, F. T.; Jin, X.; Lee, M. A.; Lee, H.; Zeng, A.; Xue, G.; Schacherl, J.; Gibson, S.; Vega, L.; Strano, M. S. ACS Nano 2020, 14, 10141-10152.

(41) Zhang, J.; Kruss, S.; Hilmer, A. J.; Shimizu, S.; Schmois, Z.; Cruz, F. D. L.; Barone, P. W.; Reuel, N. F.; Heller, D. A.; Strano, M. S. Adv. Healthcare Mater. 2014, 3, 412-423. 